\title{
COMISIÓN POR OMISIÓN. ALGUNAS CONSIDERACIONES SOBRE LA INJERENCIA COMO FUENTE DE LA POSICIÓN DE GARANTE
}

\author{
Cristóbal Izquierdo Sánchez*
}

RESUMEN: La doctrina nacional tiende a rechazar la posibilidad de que la injerencia pueda fundar la posición de garante requerida en los delitos de comisión por omisión. Se estudian críticamente los argumentos que se han planteado para considerarla inaplicable en Chile.

Palabras clave: Omisión, comisión, injerencia, omisión impropia, garante.

ABSTRACT: Under Chilean law, there has to be a guarantor for an omission to be turned into a criminal offense. The national jurisprudence has always had a tendency not to admit interference as a valid ground to justify its existence. This article studies the existing arguments and concludes that interference is not applicable in Chile.

Key words: Omission, commission, interference, inapropiate omission, guarantor.

\section{INTRODUCCIÓN}

Podría afirmarse que en los últimos años nuestro país ha experimentado un gradual avance en lo que se refiere a la admisión de la comisión por omisión tanto a nivel doctrinario como jurisprudencial ${ }^{1}$. En este último ámbito no es posible dejar de mencionar la controvertida Sentencia de la Excelentísima Corte Suprema de 4 de agosto de 1998, en la que se condena al procesado a título de comisión por omisión dolosa de homicidio ${ }^{2}$.

Sin embargo, nuestra doctrina mayoritaria rechaza la posibilidad de que la injerencia pueda fundar una posición de garante en los delitos de comisión por omisión u omisión impropia. En el presente estudio se ha hecho un trabajo de recopilación de los argumentos que nuestra doctrina ha planteado para rechazar la injerencia. Analizaremos cada uno de ellos intentando contribuir a su correcta comprensión y aportando nuestra visión del problema.

\footnotetext{
* Profesor de Derecho Penal, Pontificia Universidad Católica de Chile.

1 SÁNCHEZ TORO (2001).

${ }^{2}$ Contra Castro Muñoz (1998); ampliamente comentado por SAlim-Hanna Sepúlveda (1998) y Soto PiñeIRO (1999).
} 


\section{CONSIDERACIONES GENERALES ACERCA DE LA COMISIÓN POR OMISIÓN Y LA INJERENCIA}

En primer lugar nos ha parecido conveniente repasar brevemente lo que se entiende actualmente por delitos de comisión por omisión y las fuentes de la posición de garante. En el Derecho Penal Contemporáneo es de común conocimiento la distinción, al referirse a los delitos omisivos, entre los llamados delitos de omisión propia y los de omisión impropia. Los primeros son aquellos que están expresamente tipificados en la ley como delitos de omisión, por ejemplo, nuestro delito falta denominado omisión de socorro, previsto en el artículo 494 No 14 del Código Penal; los segundos-delitos de omisión impropia- no están expresamente consagrados en la ley como delitos omisivos, sino que se llega a ellos mediante la inversión de un tipo activo. Así, por ejemplo, el artículo 391 de nuestro Código Penal sanciona el homicidio describiendo una conducta activa: "el que mate a otro". Sin embargo, es perfectamente concebible que, por ejemplo, a una empleada doméstica que deja de alimentar hasta la muerte por desnutrición al niño pequeño que tiene bajo su cuidado, le pueda ser atribuido el delito de homicidio por omitir la administración del alimento necesario. En términos sencillos podríamos decir que comete el delito de homicidio, pero por omisión. Dejando de lado las dudas que merecen, en cuanto a su constitucionalidad estos delitos de omisión impropia ${ }^{3}$, los estudiosos del derecho penal requieren para su configuración que el omitente se encuentre en posición de garante del bien jurídico afectado por la omisión. Para evitar que se amplíe en demasía la aplicación de delitos de omisión impropia es que se han establecido en doctrina las "fuentes de la posición de garante". Son indiscutidas a nivel nacional, como fuentes de esta posición, la ley y el contrato ${ }^{4}$. El debate en Chile se centra en si puede admitirse la injerencia como fuente del deber jurídico de actuar.

Entendemos por injerencia al hacer precedente creador de un riesgo. Su fundamento, en términos sencillos, es el siguiente: quien con su conducta ha creado un riesgo, se constituye en garante de los bienes jurídicos que ha puesto en peligro. En razón de la conducta anterior creadora del riesgo, quien la ejecuta queda erigido en custodio de ese bien, surgiendo en consecuencia, el deber jurídico de actuar a fin de sustraerlo a los riesgos así generados, de suerte que, si no lo hace, el resultado típico le es imputable a título de comisión por omisión.

Basta una revisión rápida a nuestro Código Penal para constatar que no está contemplada expresamente la injerencia como posición de garante, lo cual a nadie sorprende teniendo en cuenta su antigüedad. La injerencia responde a una elaboración jurisprudencial y doctrinaria de época posterior a la de nuestro código, desarrollada en

\footnotetext{
${ }^{3}$ El profesor de la Universidad Católica de Coquimbo Raúl Carnevali Rodríguez considera superados los posibles reparos a la constitucionalidad de los delitos de comisión por omisión en la medida en que los tipos penales dejen de ser concebidos como descripciones causal naturalísticas, en su mayoría activas (no omisivas), sino como prohibiciones de índole atributivo o adscriptivo. Sus interesantes planteamientos pueden consultarse en su artículo reciente: CARNEVALI (2002) pp. 69-80.

${ }^{4}$ Politoff et al. (2003) p. 201; GARrido (2003) p. 188; CURY (2005) pp.681-682.
} 
Alemania, principalmente. Actualmente, muchos códigos penales en los que se ha elaborado una cláusula general que permite el castigo a título de comisión por omisión de los delitos de la parte especial, incluyen la injerencia como una fuente de la posición de garante. A modo de ejemplo, en el Código Penal de España en su artículo 11, se dispone: "Los delitos o faltas que consistan en la producción de un resultado solo se entenderán cometidos por omisión cuando la no evitación del mismo, al infringir un especial deber jurídico del autor, equivalga, según el sentido del texto de la ley, a su causación. A tal efecto, se equiparará la omisión a la acción: a) Cuando exista una especial obligación legal o contractual de actuar. b) Cuando el omitente haya creado una ocasión de riesgo para el bien jurídicamente protegido mediante una acción u omisión precedente" 5 . Puede apreciarse en su letra b) la consagración expresa de la injerencia. Como observa Carnevali ${ }^{6}$ estas legislaciones han adoptado un criterio formalista según el cual se otorgan directrices a nivel legal para la apreciación de la equivalencia entre los delitos de comisión y los de omisión impropia y se enumeran las situaciones que permiten considerar que se ha constituido una posición de garante. Este autor piensa que son más acertadas las soluciones de índole material-funcional en las que se supera la rigidez de los criterios formalistas. En lo que respecta a nuestro estudio, podemos observar que tanto en las tesis formalistas como en las materiales-funcionales, la injerencia es aceptada como una fuente de la posición de garante ${ }^{7}$. A nivel nacional opina en contrario Soto Piñeiro, quien afirma categóricamente, "no creemos que la referencia a la denominada "posición de garante" deba cumplir función alguna en la constitución de lo injusto de los llamados delitos de comisión por omisión" 8 .

La carencia en Chile de una norma legal expresa que permita la comisión por omisión y que haga alusión a la injerencia no permite afirmar a priori que sea por eso contraria a nuestra legislación penal vigente. Lo que ahora interesa averiguar es si en la ley nacional se consideran situaciones en que expresamente se reconozca que el hacer anterior creador de peligro establece una relación fáctica de garante. Conviene puntualizar que esto es lo máximo que podemos aspirar a encontrar en nuestro ya anticuado Código Penal, aplicándose de igual manera esta limitación a las otras dos fuentes de la posición de garante, ya enunciadas - ley y contrato- que todos aceptan en Chile. El artículo 142 del Código Penal, que castiga el delito de sustracción de un menor de 18 años, dispone en su inciso final: "Si con motivo u ocasión de la sustracción se cometiere alguno de los delitos indicados en el inciso final del artículo anterior, se aplicará la pena que en él se señala". Ese inciso final del artículo 141 dispone: "El que con motivo u ocasión del secuestro cometiere además homicidio, violación, violación sodomitica o algunas de las lesiones comprendidas en los artículos 395, 396 y $397 N^{o}$ 1, en la persona del ofendido, será castigado con presidio mayor en su grado máximo a presidio perpetuo calificado". De esta

\footnotetext{
5 También se incluye la injerencia en el artículo 13 del Código Penal de Perú. Lo mismo ocurre en el artículo 25 del Código Penal colombiano.

${ }^{6}$ Carnevali (2002) p. 78.

7 CARneVali (2002) p. 78.

${ }^{8}$ Soto Piñeiro (1999) p. 253.
} 
manera, viene a establecerse que quien sustrajo a un menor tendrá que responder como garante de la víctima de la sustracción ante eventuales atentados que pudiera sufrir. Quien sustrae a un menor lo pone en riesgo de sufrir ataques a su vida, integridad física e indemnidad sexual. Esta conducta - la sustracción- es una acción creadora de peligro que constituye al que la ejecutó, en garante del bien jurídico amenazado. El legislador no exige que los delitos que sobrevienen a la sustracción sean cometidos necesariamente por el autor del delito del artículo 142 ya que la expresión se cometiere es amplia. Ahora bien, si quien comete el delito que se suma a la sustracción es una persona distinta del sustractor, para que se verifique la figura calificada es necesario que el sustractor responda por el nuevo delito a título de dolo, dolo eventual o al menos culpa. Esto ocurriría, por ejemplo, cuando el sustractor deja a la víctima encerrada junto a un sujeto manifiestamente peligroso que da muerte al menor. No puede afirmarse, a la luz de lo que se ha expuesto que la injerencia en Chile carezca completamente de fundamento legal ${ }^{9}$. Se vislumbra cierta inclinación legislativa en orden a considerar que está en posición de garante quien, con su conducta precedente, ha creado un estado peligroso para ciertos bienes jurídicos.

\section{INJERENCIA EN EL DERECHO COMPARADO}

Al consultar las principales obras que el derecho comparado contemporáneo ofrece, nos encontramos con que la opinión absolutamente predominante estima que una de las fuentes de la posición de garante es precisamente la injerencia ${ }^{10}$. Sin embargo, figuras como Welzel opinan en contrario: "El principio jurídico sobre la posición de garante por un 'actuar precedente' empleado por la jurisprudencia actual con seguridad apodictica, es todo menos que evidente e inobjetable (...). No existe ni la más minima razón objetiva por la cual la mera causación del peligro debiera fundamentar una posición de garante"11. Debemos agregar que bastantes autores extranjeros no tratan este tema. Jakobs ${ }^{12}$ la admite como fuente de la posición de garante. En su terminología, considera que genera deberes de aseguramiento: "En tanto en cuanto la injerencia genera deberes de aseguramiento, esta es absorvida por los deberes de aseguramiento del tráfico ya tratados. Ejemplo: Quien cava una zanja en una calle pública tiene que asegurarla; quien aumenta la velocidad de un automóvil tiene que moderar la velocidad en caso necesario, etc. Pero ¿qué sucede si la víctima ya cayó en la zanja o fue arrollada por el vehículo y ahora necesita ayuda? Pues bien, también en estos casos se sigue tratando del sinalagma libertad de organizar/responsabilidad por las consecuencias. En efecto, si el mundo fue constituido de forma socialmente inadecuada mediante el comportamiento precedente, el responsable tiene que restablecer una configu-

\footnotetext{
${ }^{9}$ Seguimos para estos razonamientos la línea argumental de CURY (2005) pp. 682-683.

10 BaCigalupo (1970) p. 122 la admite limitadamente; Muñoz Conde (1996) p. 262; Muñoz Conde (1983) pp. 10-11; Rodríguez Mourullo (1978) pp. 307-308; Soler (1978) pp. 295-296; ROMEO CASABONA (1994) pp. 40-41; MEZGer (1959) p. 125.

11 WELZEL (1976) p. 297.

12 JAKOBS (2000) pp. 137-138.
} 
ración adecuada, y en verdad, no solo en tanto en cuanto a él le ha sido asignado un mundo para configurarlo libremente (aseguramiento), sino también en tanto él lo ha usurpado, lo que significa que tiene que revocar su usurpación (salvamento). Explicado en sentido figurado: La herida de la victima - a consecuencia del delito-pertenece a la organización del autor y este repara esta usurpación curando la herida o tomando las medidas oportunas para su curación".

\section{LA INJERENCIA EN LA DOCTRINA NACIONAL}

Los autores nacionales que tratan sobre la injerencia difieren en cuanto a la posibilidad de admitir el hacer precedente en Chile. Entre los partidarios de la injerencia, como fuente de un deber jurídico de actuar, encontramos a Novoa, quien se refiere a ella en los siguientes términos: "Deber impuesto por un acto precedente. Hay casos en que una situación impone una obligación de actuar en un determinado sentido al que la provocó. Por ello se entiende que el que inadvertidamente dejó encerrado en una pieza a alguien, al echar llave a la puerta, está obligado a permitirle la salida apenas repare en lo sucedido. Cuando la propia acción crea una situación de hecho que en su desarrollo puede producir un resultado que lesione bienes jurídicos, deben adoptarse medidas para evitarlo. La fundamentación de este tercer caso no es fácil hacerla en Derecho Positivo. Algunos han querido buscar apoyo en un pretendido Derecho Consuetudinario. A nuestro juicio, el sencillo principio de Derecho Natural que manda no causar daño a otro y dar a cada uno lo suyo, es suficiente fundamento"13.

Cury, por su parte, la acepta restringidamente: "Debe tratarse en primer lugar de una acción ilícita (pero no necesariamente típica) y además, dar origen a una elevada probabilidad de daño. De otro lado, solo pueden tenerse en cuenta conductas voluntarias. La negligencia no es suficiente. Al fin, tiene que resolverse caso por caso. Estas reglas generales son solo limitativas"14. Nos parecen muy valiosas las apreciaciones del profesor Cury, sin embargo, disentimos en lo que se refiere a la exigencia de que el obrar anterior generador de un riesgo deba necesariamente ser un actuar ilícito. Permítasenos, a pesar de estar analizando la opinión de la doctrina nacional, esclarecer este punto a la luz de las palabras de Jakobs 15 quien sostiene en la misma conferencia citada más arriba: "Ahora bien, ¿cómo tiene que ser el comportamiento precedente para que dé lugar a deberes de salvamento? (...) Entre los que reconocen deberes como consecuencia de la teoría de la injerencia reina unanimidad respecto a que en cualquier caso un comportamiento antijurídico origina este tipo de deberes. (...) En mi opinión, el ámbito de la injerencia se reduce en demasia si nos centramos solamente en comportamientos anteriores que sean antijurídicos (...), pero en cualquier caso parece que la regla "quien origina un riesgo especial tiene que cargar también con deberes de salvamento" es más acertada que la regla del comportamiento

\footnotetext{
13 NovOA (2005) p. 327.

${ }^{14}$ CURY (2005) p. 683.

15 JAKOBS (2000) pp. 138-140.
} 
precedente antijurídico. El Tribunal Supremo Federal alemán argumenta -al menos en sus conclusiones- en algunos casos con la fórmula general de "riesgo especial"; en efecto, solo asi puede entenderse su sentencia sobre responsabilidad por el producto: El comportamiento precedente que en esa sentencia se califica -al menos terminológicamente-como de antijuridico (la distribución del producto) es, de facto, un comportamiento conforme a Derecho, hasta hoy incluso sin importancia, pero que precisamente la sentencia define por primera vez como riesgo especial, a saber, el riesgo de lanzar un nuevo producto al mercado (BGHSt, vol. 37, pp. 117 y ss.)". Con este autor consideramos que en la injerencia no es imprescindible que el actuar precedente sea ilícito, interesante cuestión que no abordaremos en el presente estudio y que dejamos para otro posterior.

\section{PRINCIPALES ARGUMENTOS POR LOS QUE LA DOCTRINA CHILENA DESESTIMA LA INJERENCIA}

Etcheberry expone que "La doctrina nacional tiende a rechazar esta fuente"16. Nos proponemos, a continuación, analizar los principales argumentos que la doctrina chilena ha sostenido para estimar inaplicables en nuestro país las situaciones de injerencia como fuente de la posición de garante. Manifestaremos nuestra opinión sobre cada una de ellos.

\section{INCOMPATIBILIDAD ENTRE LAS HIPÓTESIS DE INJERENCIA Y LA ATENUANTE} DEL ARTÍ́CULO 11 No 7

Garrido, Politoff, Bustos, Grisolía, Matus y Ramírez ${ }^{17}$ afirman que existe una contradicción insalvable entre la atenuante del artículo 11 No 7 de nuestro Código Penal y la posición de garante fundada en la injerencia. La hipótesis de la atenuante es: "Si ha procurado con celo reparar el mal causado o impedir sus ulteriores perniciosas consecuencias". La contradicción consistiría en que la ley favorece al delincuente "premiándolo" a través de esta atenuante si intenta eliminar los efectos de un hecho delictivo. Esto sería incompatible con un deber jurídico de actuar para impedir el mal o sus ulteriores consecuencias.

Nos parece que esa incompatibilidad es aparente si se toma en cuenta que en las hipótesis de injerencia, para quien realiza la actividad generadora de peligro nace una obligación de actuar evitando la lesión del bien jurídico y, de no desplegarse esa conducta evitadora del resultado, se generará su responsabilidad penal. Se trata en la injerencia del origen o nacimiento de esa responsabilidad. En cambio, la atenuante del artículo 11 No 7 viene a disminuir la responsabilidad penal en situaciones en que dicha responsabilidad ya ha nacido. De esta manera se aprecia que la injerencia y la atenuante cubren situaciones distintas entre sí, no existiendo la contradicción que se ha querido afirmar

\footnotetext{
16 ETCHEBERry (1998a) p. 206.

17 GARrido (2003) pp. 187-189; POlitoff (1997) pp. 318-321; Bustos et al. (1993) p. 60; POlitoff et al. (2003) p. 204.
} 
entre los autores citados. Desde un punto de vista un poco distinto ${ }^{18}$, se puede agregar el siguiente argumento: la ley -interesada en la preservación de los bienes jurídicos"paga el precio" de una atenuación de la pena a fin de conseguir que el delincuente procure evitar otras consecuencias dañosas, pero de esto no se sigue lógicamente que, si así no ocurre, lo exonere de responsabilidad penal por ellas. Antes bien, por lo mismo que concede a la evitación importancia suficiente como para conceder un premio por ella, cabe suponer que su no evitación afecta al ordenamiento jurídico lo bastante como para empujarlo a irrogar una pena. La situación es semejante a la del desistimiento en la tentativa. Allí se excluye la punibilidad del que habiendo comenzado la conducta típica se detiene antes de consumar, precisamente porque interesa evitar la lesión del bien jurídico, pero ese mismo interés conduce a castigar si se consuma el delito. Nadie ha visto una contradicción entre ambas situaciones. Otra situación aún más parecida a la que se genera al aplicar la injerencia es la del desistimiento del delito frustrado, que consiste en una exclusión de la punibilidad que favorece a quien ha realizado toda la conducta típica sin llegar a consumar por causas dependientes de su voluntad. Aquí la ley nuevamente "premia" eliminando todo castigo a quien deja sin lesión el bien jurídico amenazado a pesar de haber realizado toda la conducta descrita por el tipo sin que se hayan producido los resultados exigidos por este. Por el contrario, castigará si no se evitan los resultados. Solo "premia" si despliega efectivamente una conducta evitadora del resultado, y en la medida en que haya sido exitosa esa evitación de la lesión del bien jurídico ${ }^{19}$.

\section{EN LAS HIPÓTESIS DE INJERENCIA NO PUEDE APRECIARSE UNA OMISIÓN, SINO SOLO UNA ACCIÓN}

Etcheberry $^{20}$ al referirse a la injerencia afirma lo siguiente: "si el daño efectivo sobreviene como consecuencia del riesgo creado por el agente, no puede decirse en verdad que provenga de la mera omisión de este en limitar el riesgo, sino en su actividad positiva cuando lo creó". De esta manera no solo sostiene que la injerencia es inaplicable en Chile, sino que, contrariando la opinión mayoritaria del derecho comparado, niega que en estas hipótesis de injerencia pueda apreciarse una verdadera omisión.

En la injerencia, efectivamente debe haber una actividad anterior creadora de riesgo, pero Etcheberry olvida que es en virtud de la posterior omisión de la acción que podría haber evitado el resultado que se lesiona el bien jurídico, y no por la sola actividad precedente. El hacer anterior no llega a producir la lesión del bien, sino que solo genera la puesta en peligro. Es relevante la actividad precedente en cuanto antecedente que constituye en garante, pero lo típicamente relevante es la omisión de la acción esperada, en otras palabras, la acción omitida que hubiera evitado el resultado. Las

\footnotetext{
18 CURY (2005) p. 682.

19 Seguimos en lo que se refiere al desistimiento, entre otros autores nacionales, a CURY (2005) p. 571; POLITOFF et al. (2003) p. 384.

${ }^{20}$ ETCHEBERRY (1998a) p. 206.
} 
hipótesis de injerencia permiten que se configuren tipos de comisión por omisión: el tipo exige para perfeccionarse, que se produzca un cambio en el mundo exterior que la acción omitida podría haber evitado. Da la impresión de que Etcheberry incurre, en cierta medida, en el error de los causalistas que buscaban, sin llegar a lograrlo satisfactoriamente, un vínculo de índole causal entre la omisión y el resultado para los delitos de comisión por omisión. Así, llega a sostener que el daño no proviene de la mera omisión, sino de la actividad positiva anterior. En este sentido, es efectivo que el daño no proviene de la omisión, no es la omisión la que causa el daño. Esto es cierto porque un no hacer nada causa, de la omisión nada proviene, entendido causalmente.

La cuestión relevante no es de carácter causal, sino normativa. La atención debe centrarse en si la acción omitida hubiera evitado el riesgo. Lo peculiar es que en las hipótesis de injerencia el riesgo es creado por una conducta anterior de quien posteriormente omite la acción evitadora. El delito de comisión por omisión en que opera la injerencia se verifica no por la conducta anterior sino por la posterior omisión de la acción debida.

En la práctica, la apreciación de un delito activo o de comisión por omisión no es fácil y sus límites no siempre están del todo claros, pues en el acaecer ordinario se mezclan constantemente el causar y el no impedir. El asesino que apuñala a su víctima dejando luego que se desangre hasta morir, ha cometido un delito de acción, pero, sin duda, tan eficaz como la puñalada, en la producción de la muerte, ha sido el no contener la hemorragia. El caso del cirujano que practica la incisión en el vientre de su paciente para llevar a cabo una intervención quirúrgica y que luego omite practicar las suturas precisas para llevar a buen término la operación, con la consecutiva hemorragia y muerte, es estructuralmente similar y, sin embargo, es sumamente dudosa su solución. ¿Debe considerarse como un delito activo o puede apreciarse una comisión por omisión? Más se presenta esta dificultad en el supuesto del automovilista que conduce su vehículo y por no frenar a tiempo da muerte a una persona. La complicación en el enjuiciamiento de estos casos existe ya que para que exista un delito deben concurrir todos sus elementos en el momento de verificarse la conducta. La precisión necesaria ${ }^{21}$ se consigue teniendo en cuenta que el delito no es una suma de varios componentes, sino un fenómeno global. Por ello, en estos casos dudosos hay que tener en cuenta, para la fijación del momento en que comienza el actuar jurídico-penalmente relevante, la intención del sujeto en los delitos dolosos. Así, por ejemplo, si el médico al comenzar su intervención tenía la intención de dejar que se desangrara el "operado", estamos ante un hacer positivo, ante un claro delito de acción. La situación será distinta si la intención nace después de haber practicado la incisión. En esa hipótesis, estaremos ante una comisión por omisión. En los delitos culposos, no es posible usar como punto de referencia la intención del sujeto, como se propone para los delitos dolosos. Por tanto, habrá que acudir a otros criterios: será necesario distinguir entonces según que se man-

\footnotetext{
${ }^{21}$ Seguimos, para estas argumentaciones a RODRígUEZ DEVESA (1995) pp. 388 ss.
} 
tenga un hacer activo, susceptible o no de control en el momento de producirse el resultado, de aquellos supuestos en que las fuerzas naturales quedan abandonadas a sí mismas por un hacer precedente del sujeto. Por ejemplo, atropellar a una persona por no haber frenado a tiempo es un delito de acción; dejar un vehículo de motor sin freno de mano en una pendiente y la causación de la muerte por el vehículo que se desliza por la calzada a causa de su propio peso, sería una comisión por omisión culposa en la medida en que concurran todos sus requisitos.

\section{EL PENALISTA ITALIANO FILIPO GRISPIGNI}

Politoff, en su obra particular, en su obra conjunta con Bustos y Grisolía y en su posterior libro Lecciones de Derecho Penal Chileno ${ }^{22}$, rechaza la posibilidad de aplicar la injerencia en Chile. En todas estas obras se cita al penalista italiano Grispigni, quien con cierta ironía afirma, para desechar las hipótesis de injerencia, que "quien ocasiona por culpa un incendio no se convierte en autor doloso porque no lo apaga". Esta frase tan lógica no impide la aceptación de la injerencia como fuente de la posición de garante en los delitos de omisión impropia. Un poco de claridad en este sentido puede darnos la transcripción completa de la cita del penalista que en su Tratado de Derecho Penal Italiano, en el capítulo sobre la acción y la omisión, afirma: "Così chi cagiona per colpa un incendio, non diviene autore doloso di questo se non lo smorza, perchè si tratterebbe di dolus subsequens" 23 . Estos autores que mencionan a Grispigni, olvidan el final de la frase y su importancia: "quien ocasiona por culpa un incendio no se convierte en autor doloso porque no lo apaga, porque entonces se trataria de un dolo subsequens" 24 . Grispigni no hace más que recordarnos el primero de los conocidos requisitos cognocitivos del dolo: debe ser actual, esto es, debe estar presente al momento de la ejecución de la conducta. Un dolo posterior es irrelevante típicamente, sería un dolo subsequens ${ }^{25}$.

Efectivamente, nadie podría discutir que quien por culpa genera un incendio no se convierte en autor doloso por no apagarlo, pues el elemento culpa o dolo queda definido o fijado en el momento de la ejecución del delito y no es relevante, para la configuración de ese delito, lo que ocurra después. No tiene importancia el posterior " $n o$ apagar las llamas" en relación con ese delito concreto de incendio y su calificación culposa. En cambio, sí que tiene importancia la abstención ("no apagarlo") y el posible dolo o culpa manifestados con posterioridad, para la configuración de un nuevo delito. Un ejemplo podrá ilustrar esta última idea y servirá para constatar que la afirmación de Grispigni y las hipótesis de injerencia son perfectamente compatibles.

Supongamos por un momento que una persona bromeando juega con una pistola cargada en presencia de otra que asustada pide al bromista que no siga con su juego porque puede ser peligroso para ambos. Insiste el portador del arma con su arriesgado

22 Politoff (1997) p. 320; Bustos et al. (1993) p. 59; POlitoff et al. (2003) p. 203.

23 Grispigni (1952) p. 55.

${ }^{24}$ La traducción completa de la frase la encontramos en JiMÉNEZ DE AsÚA (1974) p. 426.

25 CURY (2005)p. 309; siguiendo otra sistematización del delito, POlitoff et al. (2003) p. 259. 
pasatiempo hasta que, por fin, se le escapa un disparo, con tan mala fortuna que impacta a su compañero provocándole una herida no letal, pero sí muy grave, que lo deja inconsciente. El que disparó se retira temeroso por lo que ha sucedido, sabiendo que el estado de la víctima de la lesión es preocupante y que, si no es atendido con prontitud, podría morir desangrado. El desafortunado bromista deja pasar el tiempo y nada hace por salvar la vida del herido que fallece desangrado varias horas más tarde. Aplicando la "fórmula" Grispigni a este caso, podemos considerar que por no atender a la víctima del disparo, el imprudente que jugaba con el arma no se convierte en autor doloso de las lesiones que le provocó. La ausencia de atención a la víctima en nada afecta al delito imprudente porque afirmar lo contrario sería admitir un dolo subsequens. Efectivamente, queda el delito fijado en su carácter culposo al momento de su ejecución, pues no tenía la intención de matar al jugar con el arma. Parafraseando al autor italiano, en este ejemplo podríamos afirmar que "quien ocasiona por culpa unas lesiones no se convierte en autor doloso de esas lesiones por no atender al herido". Estando de acuerdo con Grispigni, podemos dar un paso más para afirmar que es compatible este planteamiento con la injerencia: por el disparo imprudente quedó perfectamente configurado el delito culposo de lesiones. Ahora bien, este hacer anterior (disparo culposo) ha constituido a su ejecutor en garante de la vida de la víctima, tomando en cuenta la gravedad de las lesiones. Él creó, para la víctima del impacto, el peligro de perder su vida naciendo consecuencialmente el deber jurídico de actuar evitando ese resultado. ¿Concurso real de delito imprudente de lesiones con una omisión impropia de homicidio doloso? Se dan todos los requisitos de las lesiones culposas, pero también se verifican los de una comisión por omisión dolosa respecto del homicidio en que un hacer precedente genera la posición de garante. Recordemos que la omisión dolosa exige que el omitente conozca la situación de peligro para el bien jurídico y decida conscientemente no intervenir en los cursos causales que evitarían el resultado ${ }^{26}$. En el caso propuesto, no debe apreciarse un concurso real sino aparente de leyes ya que si bien lo que constituye como garante al que disparó imprudentemente es precisamente el delito culposo de lesiones, tiene aplicación el principio de absorción o consunción que, fundado en el principio de insignificancia, resuelve satisfactoriamente casos como el propuesto ${ }^{27}$. La verificación de uno de los hechos abarcados por las normas en concurso aparente -lesiones culposas- resulta insignificante en relación con el hecho que prevalece -comisión por omisión dolosacuya intensidad criminal absorbe la del hecho copenado desplazado 28 . La comisión por omisión del delito de homicidio doloso abarca el disvalor delictivo del cuasidelito de lesiones, hecho copenado desplazado. Hacemos presente que el carácter culposo del hacer precedente queda sin variación al aplicar la injerencia. No existe, por lo tanto, la

\footnotetext{
${ }^{26}$ CURY (2005) p. 676 aunque considera que no existe una omisión dolosa propiamente tal.

27 Politoff et al. (2003) p. 457.

28 POLITOFf et al. (2003) p. 462 ss.; con una terminología algo diversa CURY (2005) pp. 669-670; NovOA (2005) pp. 255-258.
} 
contradicción que la doctrina chilena ha querido destacar, entre la cita transcrita de Grispigni y las hipótesis de injerencia.

A mayor abundamiento, permítasenos el siguiente ejercicio, valiéndonos de la misma figura delictiva citada por el penalista italiano. En Chile el delito de incendio se encuentra en el Título IX del Código Penal que castiga los delitos contra la propiedad. El artículo 476 dispone que "Se castigará con presidio mayor en cualquiera de sus grados: 3. El que incendiare bosques, mieses, pastos, monte, cierros o plantios". Esta figura es dolosa, de tal manera que quien por culpa incendia un bosque queda, en principio, impune a título de incendio, a menos que se castigue por el artículo 495 No 21 por daños culposos y sin perjuicio de otra posible figura culposa del artículo 22 de la Ley de Bosques. Al no apagarlo, siguiendo a Grispigni, hay que afirmar que no se transforma en autor doloso del mismo delito de incendio. Analicemos el siguiente caso, a la luz de nuestra legislación: una persona culposamente deja una fogata a medio apagar en un pequeño bosque que se encuentra en un condominio habitado. Advierte más tarde que ha provocado un incendio. Regresa al lugar que arde en llamas y se percata de que un niño de pocos meses se encuentra abandonado en una esquina del bosque y está en riesgo de morir calcinado. Pudiendo salvarlo no ejecuta la acción salvadora. ¿ Se le aplica el artículo 474 que dispone: "El que incendiare edificio, tren de ferrocarril, buque u otro lugar cualquiera, causando la muerte de una o más personas cuya presencia alli pudo prever, será castigado con presidio mayor en su grado máximo a presidio perpetuo"? No es aplicable, ya que el sujeto no pudo prever la presencia del niño abandonado al momento de provocar culposamente el incendio. También excluimos la omisión de socorro del artículo 494 No 14 ya que en el caso propuesto el bosque se encuentra en medio de un condominio habitado. Parece correcto considerar que al haber producido las llamas y advertido con posterioridad la presencia del niño en peligro, quien no apagó correctamente la fogata, por su hacer precedente creador de un riesgo, queda erigido en garante de la vida del niño desde el momento en que habiendo él mismo creado el riesgo, advierte el peligro para la vida del niño. Al sujeto que provocó culposamente el incendio la sociedad no puede considerarlo uno más de quien nada se espera. Su hacer precedente creador del riesgo lo ha transformado en el custodio de la vida del niño desde que toma conocimiento de su presencia en el bosque. Consideramos que no basta con que exista el deber de actuar para afirmar la posición de garante siendo indispensable que el omitente efectivamente en el caso concreto la haya asumido cuando comienza la situación de peligro $^{29}$ o mientras esta persiste. En la hipótesis planteada, si no hubiera regresado no habría conocido la presencia del menor y no habría tomado conocimiento ni asumido la posición de garante. Al volver y asumir la posición de garante por su hacer precedente creador del riesgo, le es atribuible el homicidio doloso por omisión en la medida en que omita las acciones salvadoras que pudo realizar.

29 Politoff et al. (2003) p. 204. 


\section{Ciertos artículos del Código Penal eXCluirían la POSibilidad de ADMITIR LA INJERENCIA}

Garrido rechaza la injerencia en Chile, fundándose principalmente en el argumento de la atenuante del artículo 11 No 7 , pero agrega como razón para desecharla que "tipos particulares establecidos en el C.P., como el de los arts. 352, 492 y otros análogos, se contraponen a la posibilidad de que en nuestro ordenamiento la posición de garante tenga como fuente el hacer precedente, toda vez que en las situaciones regladas en esas normas, si el resultado fuera muerte, correspondería imponer al omitente la sanción del homicidio doloso; sin embargo la ley no sigue tal criterio y los sanciona como tipos especiales. Al conductor que atropella a un transeúnte y luego huye sin prestarle ayuda, si fallece posteriormente el lesionado por falta de auxilio oportuno, se le castiga como autor del delito culposo de homicidio, pero no de un homicidio doloso por omisión" 30.

Este autor propone un ejemplo por el que parece descartar toda posibilidad de una omisión. De esta manera refuerza la idea ya explicada (2.) de que no es siempre fácil distinguir entre el hacer y el no impedir. Para solucionar este problema nos parecen valiosos los criterios ya expuestos de Rodríguez Devesa. Garrido plantea problemas muy interesantes. Trataremos en primer lugar el que se refiere al artículo 492 de nuestro Código Penal: "Las penas del Artículo 490 se impondrán también respectivamente al que, con infracción de reglamentos y por mera imprudencia o negligencia ejecutare un hecho o incurriere en una omisión que, a mediar malicia constituiría un crimen o un simple delito contra las personas". Debe tenerse en cuenta que el art. 492 regula hipótesis siempre culposas y nunca dolosas. La ley no impone como pena la del delito de homicidio doloso si resulta la muerte por un atropello culposo, pues el artículo 492 regula y sanciona exclusivamente tipos culposos cometidos contra las personas. Sin embargo, es posible distinguir casos que determinarán la apreciación de un delito activo culposo de otros en los que un delito de comisión culposo precede a una posterior omisión impropia culposa o dolosa, según corresponda. Así, por ejemplo, un atropello culposo en automóvil que provoca instantáneamente la muerte, es claramente un homicidio activo culposo al que la ley impone una pena especial que no es la del homicidio doloso, lo cual es de toda lógica. Hasta aquí no se vislumbra ninguna incompatibilidad con las hipótesis de injerencia. Ahora bien, la situación de hecho es distinta y, por lo tanto, distinta será la calificación del caso, si el atropello culposo deja malherida a la víctima y el conductor que ha advertido lo ocurrido se da a la fuga sin prestar el auxilio debido y, a consecuencia de esto, más tarde -después de varias horas- resulta la muerte del afectado. Es perfectamente sostenible que el atropello imprudente ha creado una posición de garante por el hacer precedente creador de un riesgo para la vida del transeúnte atropellado. Es por la omisión del auxilio que se genera la muerte. El conductor puede encontrarse en dos posiciones subjetivas respecto de la muerte: a) puede considerar que las lesiones que ha provocado culposamente por el atropello no son lo suficientemente

30 GARrido Montt (2003) p. 189. 
graves como para provocar la muerte; si tiene una base objetiva para confiar en que no se producirá la muerte, al producirse esta, solo le será atribuible a título de culpa consciente; b) el conductor representándose como posible la muerte puede desecharla careciendo de base objetiva - por la severa gravedad de las lesiones, por ejemplo- o bien, puede retirarse y aceptar la posibilidad del deceso del atropellado. En este último caso, incurre en una comisión por omisión dolosa en la que el dolo es eventual ${ }^{31}$. Tanto para a) como para b) el hacer anterior consiste en un delito culposo de lesiones que es absorbido por la posterior comisión por omisión de homicidio (ver solución propuesta en 3.)

El artículo 352 del Código Penal, que castiga el abandono de personas desvalidas, plantea un supuesto que sería incompatible con la injerencia, según Garrido. Puede ayudar la cita expresa de esa disposición legal para el análisis de la cuestión: "El que abandonare a su cónyuge o a un ascendiente o descendiente, legitimo o ilegitimo, enfermo o imposibilitado, si el abandonado sufriere lesiones graves o muriere a consecuencia del abandono, será castigado con presidio mayor en su grado minimo". Puede apreciarse que para que se verifique este delito, el resultado -lesiones graves o muerte- debe ser siempre imputable a culpa de su autor y nunca a dolo, porque si así ocurriere, se aplicarían los correspondientes delitos dolosos de lesiones graves u homicidio y no el art. $352^{32}$. Nuevamente se soluciona el caso mediante la absorción o consunción. Efectivamente, "si el resultado fuera muerte, correspondería imponer al omitente la sanción del homicidio doloso", como apunta Garrido, pero precisando que solo en la medida en que este resultado sea abarcado por el dolo del autor se aplicaría la sanción del art. 390 o 391, según corresponda. Todo lo anterior no se refiere a la injerencia, pues en el artículo 352 es la misma ley la que directamente establece la posición de garante en razón de deberes de asistencia familiar, por la relación que existe entre el autor y la víctima.

\section{NORMAS DE LA LEY DEL TRÁNSITO IMPIDEN ACEPTAR LA INJERENCIA ${ }^{33}$}

Como argumento que refrendaría la incompatibilidad entre el hacer precedente creador de un riesgo como fuente de la posición de garante y la atenuante del artículo 11 No 7, los autores Politoff, Matus y Ramírez afirman "y aún más, en el caso de los accidentes del tránsito, según los arts. 173 y 183 de la Ley de Tránsito, No 18.290, el abandono del lugar donde ocurrieren no convierte los cuasidelitos cometidos en delitos de lesiones $u$ homicidios dolosos, sino simplemente configura una presunción de responsabilidad por las lesiones o muertes culposas causadas". Nos parecen suficientes como argumentos los señalados más arriba (3.) ya que la ley simplemente presume la responsabilidad penal y admite la prueba del dolo en una comisión por omisión por la posterior muerte. Podría configurarse una omisión impropia en la medida en que se den todos los presupuestos ya explicados en los que opera la injerencia.

\footnotetext{
${ }^{31}$ Hacemos propios los conceptos de culpa y dolo eventual que aporta NÁQUIRA (1998) pp. 144-145 y 166.

32 ETCHEBERRY (1998b) p. 17.

33 Politoff et al. (2003) p. 204.
} 


\section{CONCLUSIÓN FINAL}

Hemos abordado los argumentos que la doctrina nacional propone para rechazar la injerencia en nuestro país. Como se fue explicando, todos ellos nos parecen insuficientes para afirmar su inadmisibilidad. A través de este trabajo esperamos haber colaborado en orden a que nuestros autores y tribunales estimen progresivamente que el hacer precedente creador de un riesgo puede fundar en Chile un deber jurídico de actuar en virtud de la posición de garante que crea para los delitos de comisión por omisión.

\section{BIBLIOGRAFÍA CITADA}

BaCigalupo, Enrique (1970): Delitos Impropios de Omisión: con estudio analitico del tema en la jurisprudencia argentina referente a los delitos de homicidio, lesiones, estupro y estafa (Buenos Aires, Ediciones Pannedille) 173 pp.

Bustos, Juan, Grisolía, Francisco y POlitoff, Sergio (1993): Derecho Penal Chileno. Parte Especial: Delitos contra el individuo en sus condiciones físicas (Santiago, Editorial Jurídica de Chile, 2a Edición) 293 pp.

Carnevali Rodríguez, Raúl (2002): "El Delito de Omisión. En particular, la Comisión por Omisión", en: Revista de Derecho, № 9, Universidad Católica del Norte, Campus Guayacán, pp. 69-80.

CurY, Enrique (2005): Derecho Penal, Parte General (Santiago, Ediciones Universidad Católica de Chile, 7a Edición) 812 pp.

EtCheberry, Alfredo (1998a): Derecho Penal, Parte General (Santiago, Editorial Jurídica de Chile, $3^{\text {a }}$ Edición, Tomo I) $361 \mathrm{pp}$.

Etcheberry, Alfredo (1998b): Derecho Penal. Parte Especial (Santiago, Editorial Jurídica de Chile $3^{\text {a }}$ Edición, Tomo IV) 382 pp.

Garrido Montt, Mario (2003): Derecho Penal, Parte General, Nociones Fundamentales de la Teoría del Delito (Santiago, Editorial Jurídica de Chile, 3a Edición, Tomo II) 358 pp.

Grispigni, Filippo (1952): Diritto Penale Italiano (Milano, Dott. A. Giuffrè Editore, Volume Secondo) $488 \mathrm{pp}$.

JAKOBS, Günter (2000): "La Omisión: estado de la cuestión" (Traducc. Javier SánchezVera Gómez-Trelles, en VV.AA. Sobre el estado de la teoría del delito (Madrid, Civitas Ediciones, $1^{\text {a }}$ edición) $207 \mathrm{pp}$.

Jiménez De AsúA, Luis (1974): Tratado de Derecho Penal (Buenos Aires, Editorial Losada Tomo III) $1102 \mathrm{pp}$.

Mezger, Edmundo (1959): Derecho Penal. Libro de Estudio. Parte General (Buenos Aires, Editorial Bibliográfica Argentina, 6a edición) Tomo I, 459 pp.

Muñoz Conde, Francisco (1996): Derecho Penal. Parte General (Valencia, Editorial Tirant lo Blanch, 2a Edición) 549 pp.

Muñoz Conde, Francisco (1983): Derecho Penal. Parte Especial (Sevilla, Publicaciones de la Universidad de Sevilla, 5a Edición) 764 pp.

NÁQuira, Jaime (1998): Derecho Penal. Teoría del Delito (Santiago, Editorial Mc GrawHill, Tomo I) $480 \mathrm{pp}$. 
NovoA, Eduardo (2005): Curso de Derecho Penal Chileno (Santiago, Editorial Jurídica de Chile, $3^{\text {a }}$ Edición, Tomo I) 585 pp.

Politoff, Sergio (1997): Derecho Penal (Santiago, Editorial Jurídica ConoSur) 673 pp.

Politoff, Sergio, Matus, Jean Pierre y Ramírez, María Cecilia (2003): Lecciones de Derecho Penal Chileno. Parte General (Santiago, Editorial Jurídica de Chile, 2a edición) 613 pp.

Rodríguez Devesa, José María y Serrano Gómez, Alfonso (1995): Derecho Penal Español. Parte General (Madrid, Artes Gráficas Carasa, 18 Edición) 1071 pp.

Rodríguez Mourullo, Gonzalo (1978): Derecho Penal. Parte General (Madrid, Editorial Civitas) $357 \mathrm{pp}$.

Romeo Casabona, Carlos María, Jornadas Hispano-Alemanas de Derecho Penal (1994), "Límites de los delitos de comisión por omisión" en: Omisión e imputación objetiva en Derecho Penal (Universidad Complutense de Madrid) 124 pp.

Salim-Hanna Sepúlveda, Roberto (1998): "Notas a un Fallo de Homicidio", en Revista de Derecho de la Universidad Finis Terrae, Año II, No 2: pp. 9-30.

Soler, Sebastián (1978): Derecho Penal Argentino (Buenos Aires, Editorial TEA, Tomo I) $386 \mathrm{pp}$.

Soto PiÑeiro, Miguel (1999): "Una Jurisprudencia Histórica: hacia el reconocimiento del "principio de culpabilidad" en el Derecho penal chileno", en: Revista de Derecho de la Universidad Finis Terrae, Año III, No 3: pp. 233-253.

Welzel, Hans (1976): Derecho Penal Alemán (Santiago, Editorial Jurídica de Chile, $11^{\mathrm{a}}$ Edición) 403 pp.

\section{JURISPRUDENCIA CITADA}

Sánchez Toro (2001): Corte Suprema 30 de enero de 2001 (solicitud de declaración de sentencia injustificadamente errónea o arbitraria) Rol No 4.576-01[en línea] [fecha de consulta: 6 de julio de 2006] disponible en Base de Datos LexisNexis, www.lexisnexis.cl

Contra Castro Muñoz (1998): Corte Suprema 4 de agosto de 1998 (recurso de casación en la forma), Revista Gaceta Jurídica, 218, agosto 1998, pp. 96 ss. 
